\title{
Model for Measuring Post-Harvest Technological Capability of Paddy Farmers in Dealing with Climate Change
}

\author{
Anggara Hayun $\mathrm{A}^{1}$, Machfud ${ }^{2}$, Sutrisno ${ }^{2}$, Ani Suryani ${ }^{2}$ \\ ${ }^{1}$ Young Researcher, The Agency for The Assessment and Application of Technology, \\ ${ }^{2}$ Post Graduate Program, Faculty of Agricultural Technology \\ Bogor Agricultural University
}

\begin{abstract}
Extreme weather has been occuring recently in various regions in Indonesia. In the early 2013, this condition has caused flood in Karawang district. The increasing extreme climate indicates that climate change has occurred. Climate change, in the form of high/low rainfall, erratic rainfall or changes in the rainy/dry season, has become problem to paddy farmers in Karawang district. Problem faced by farmers due to climate change is the increase of paddy post-harvest losses. Technological capability of farmers is one of the main factors that play important role in facing such condition. Measurement of post-harvest technological capabilities of paddy farmers in dealing with climate change is carried out using six criteria, i.e the production capability, investment capability, capability to make small changes, capability to make major changes, marketing capability, and capability to create network. The methods used to measure the technological capabilities are the Analytical Hierarchy Process (AHP) and Non Numeric Multi Expert Multi Criteria Decision Making (ME-MCDM). This study reveals the level of farmer post-harvest technological capabilities in dealing with climate change and provides technology policy recommendation.
\end{abstract}

Key Words:Climate change, technological capability, level of technological capabilities, policy recommendation

\section{INTRODUCTION}

Technological capability plays very important role in dealing with climate change. It is also important for technology learning. With good technology skills, technology development can be conducted effectively, adaptable, able to improve and to create new technologies themselves (Lall, 1992; Lall, 1993, Bell and Pavitt, 1993, Kim 1999, Dutrenit, 2004, Iammarino et al , 2008).

There are some different definitions of technological capabilities. According to Kim (1997), technological capability is the ability to make use of technological knowledge effectively as an effort to assimilate, use, adapt and modify the available existing technologies. Technological capability is the result of interactive learning and interaction among a number of actors. Szogs (2010) stated that technological capability is the ability to find and select the most appropriate technology, among the existing ones that are available, to be assimilated, as well as all activities related to the creation of new knowledge.

Bell \& Pavitt (1993) said that technological capability is the ability to perform technical change. Technological capability reflects the dynamic condition of the company resulting from the process of technology learning. Ernst et al (1998) developed the technological capability in production capability, investment capability, marketing capability, capability to create linkages, capability to make small changes, and capability to make major changes.

According to Rokhani (2007), paddy post-harvest activities includes harvesting, collecting/accumulating, threshing, transporting, drying, storing, and milling. Iswari (2012) divided paddy postharvest activities into four stages which include harvesting, threshing, drying, and milling. While Setyono (2010) classified paddy post harvest activities into nine stages, i.e threshing, drying, transporting, milling, storing, quality standardizing, processing, and waste handling.

Postharvest activities in this study are focused on harvesting, threshing, drying, and storing. Milling activity is not excluded in this research with the reason that it is currently carried out by the milling industry, and the technological capability problem of milling activity nowadays is due to the obsolete milling machine so that the action required is the revitalization of the paddy milling industry (Taher 2010). Transportation activity is also not included as the the focus of this research since grain transportation activities do not require significant improvement of technological capability.

Postharvest technologies for the post-harvest activities that can be implemented respectively include:

1. Harvesting activities: ani-ani (a tool for cutting paddy), sickle, serrated sickle, paddy mower, reaper, and combine harvester. 
2. Threshing activity: trampling, banging, pedal thresher, power thresher, and combine harvester.

3. Drying activities: uncovered area, drying area, tarp/plastic covered drying area, dryer (flat bed dryer /dryer box/vertical dryer), and silo integrated dryer.

4. Storage activities: granary, canned/gunny/plastic bags in the warehouse, IRRI high quality sacks in warehouse, silos, and in store dryer.

Climate change, according to the Las et al (2011), is the condition where the magnitude and/or intensity of some climatic elements tend to change or deviate from its dynamics and average conditions toward a certain direction (increasing/decreasing). Change in rainfall pattern is the most important indicator to identify whether climate change has occurred in a certain area. Adibroto et al (2011) found that changes in rainfall pattern are characterized by the late coming of rainy season and the early end of rainy season. The rainy season occurs in shorter period with high rainfall intensity.

The problem for the farmers is whether they are able to deal with this climate change characterized by a shorter period of rainy season with high intensity of rainfall. Technological capability of farmers in dealing with climate change is very crucial in order to avoid the increasing loss of weight and the decreasing of post-harvest paddy quality. This issue underlies the research to develop a model for measuring farmer post-harvest technological capability in dealing with climate change.

This study aims to find out the level of farmer post-harvest technological capability in dealing with climate change and to provide recommendation of required technology policy. The technological capability is specified in five levels, i.e. very low, low, medium, high, and very high. These technological capability levels are related to the level of technology component to produce the expected technological capabilities. The levels of farmer post-harvest technological technology level in dealing with climate change that have been identified can be used to develop technology policy recommendations to improve the level of farmer post-harvest technological capability in dealing with climate change.

\section{RESEARCH METHOD}

\section{Research Framework}

Model for measuring post-harvest technological capability of paddy farmers in dealing with climate change is a model which is developed using intelligence system approach. Intelligence system approach is required to imitate the expertise of experts and implement it to solve problems faced by farmers in dealing with extreme climate change. The extreme climate change in form of high and erratic rainfall becomes a serious problem for farmers. This issue is complex and unstructured so that soft system method is required to manage it (Eriyatno \& Sofyar 2007).

This study is originated from an attempt to address problems faced by paddy farmers due to extreme climate change by identifying some issues, i.e. how is farmer post-harvest technological capability in dealing with climate change and what technologies are required to improve the farmer post-harvest technological capability in maintaining continuity of rice supply with good quality and quantity. The conceptual framework of this study can be seen in Figure 1.

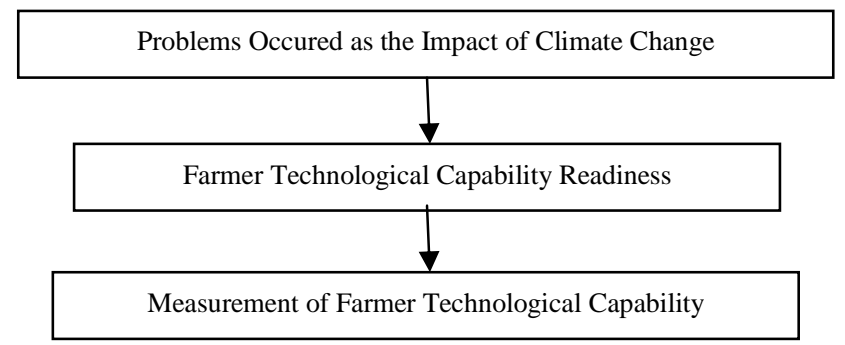

Figure 1. Conceptual Framework

The framework of model for measuring post-harvest technological capability of paddy farmers in dealing with climate change is formulated using criteria of technological capability level measurement model developed by Ernst et al (1998). The model consists of the determination of criteria and sub-criteria, measurement of technology capabilities, and technology policy recommendation. The framework model can be seen in Figure 2. 


\section{Research Framework}

The stages of model for measuring post-harvest technological capability of paddy farmers in dealing with climate change consist of determination of purpose of the study, problem identification, data collection, aggregation of level of importance, Determination of fuzzy linguistic label of criteria and sub-criteria, fuzzy assessment of post-harvest activities, determination of the level of technological capabilities, and technology policy recommendation. The output of this model is the level of farmer post-harvest technological capability in dealing with climate change and technology policy recommendation. Figure 3 shows the complete stages of the model.

\section{Data Collection}

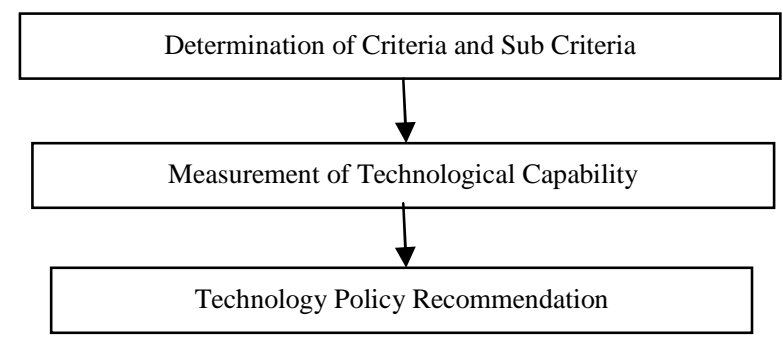

Figure 2. Framework Model

Primary and secondary data are required in this study of Model for Measuring Paddy Farmer Postharvest Technological Capability in Dealing with Climate Change. Secondary data was obtained from journals, as well as from researches with the similar subject carried out by the government institutions which are also the object of the study such as Ministry of Agriculture, BMKG (Meteorology and Climatology Agency), BPPT (Agency for the Assessment and Application of Technology), the Ministry of Research and Technology, Bulog (National Logistics Agency), and Gapoktan (Farmers Association). As for the primary data, it was collected through field observation to the locations of paddy farming in Karawang district, in-depth interviews with representatives of farmers/Gapoktan, government, universities and R\&D institutions, and experts.

\section{Data Processing and Data Analysis}

The methods for data processing used in this study are as follows:

- Analytical Hierarchy Process (AHP), used to determine the weight of technological capability criteria and sub-criteria.

- Multi-Expert Multi-Criteria Decision Making with Ordered weighed Average (OWA), used to determine the level of technological capabilities using the aggregation of fuzzy linguistic label and fuzzy assessment of post-harvest activities.

Analytical Hierarchy Process (AHP) is used to provide the relative weights of the multiple criteria or subcriteria intuitively using pairwise comparisons. The resulted weight is converted into fuzzy linguitic label by using triangular fuzzy number membership function. Weight which is located at the intersection of two fuzzy membership functions have two fuzzy values. Two fuzzy values are then conducted a comparison. Membership value fuzzy the largest is the value of label linguistic fuzzy. To determine fuzzy membership value, it is used Triangular Fuzzy Number (TFN) membership function. Triangular fuzzy number membership function can be seen in Figure 3.

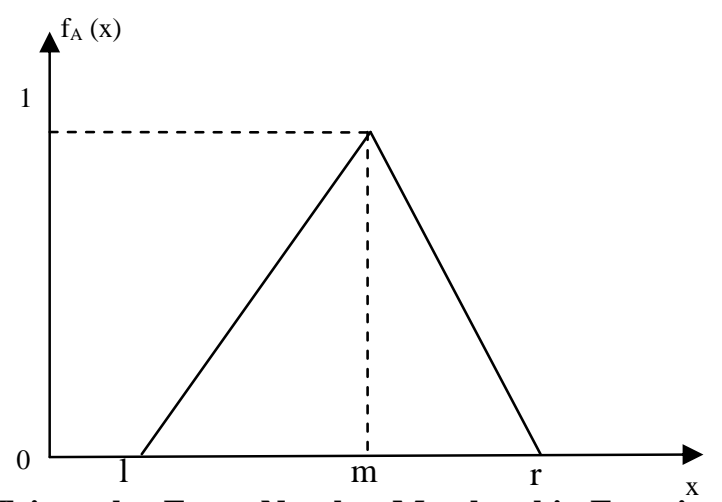

Figure 3. Triangular Fuzzy Number Membership Function

TFN rules are also used for fuzzy rating of paddy farmer post-harvest activities. Fuzzy Rating of paddy farmer postharvest activities and fuzzy linguistic label are represented using TFN membership function as shown in Figure 5. 


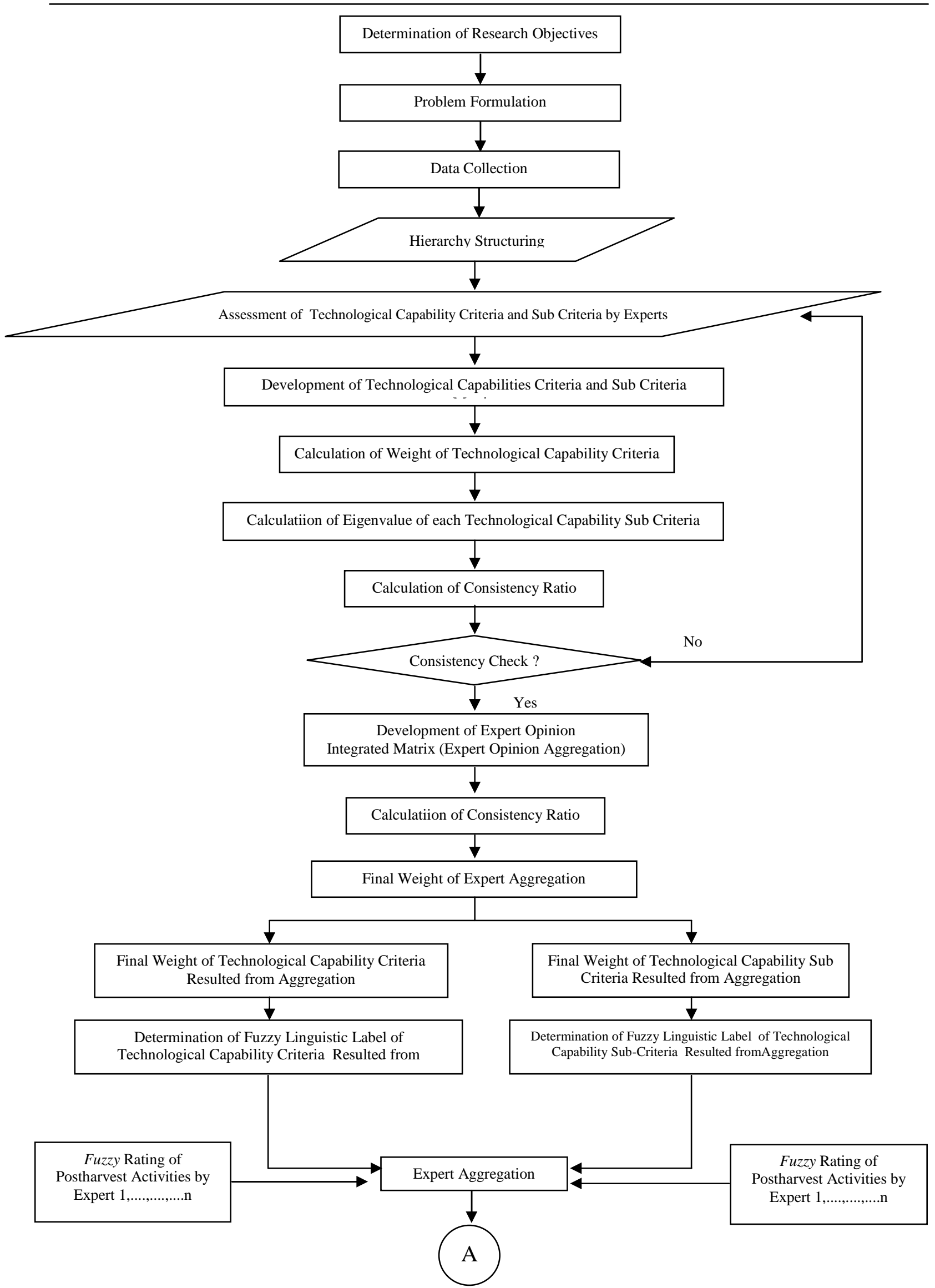

Figure 4. Research Flowchart 


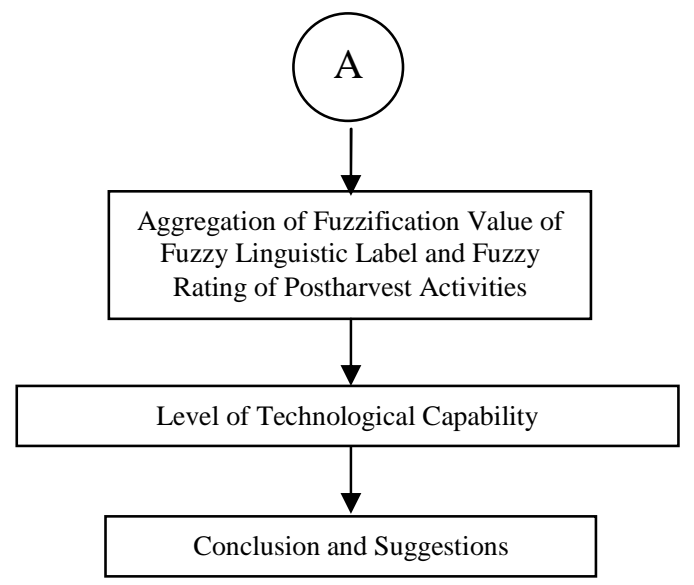

Figure 4. Research Flowchart (Continuation)

According to Wang et al (2008), the value of $\mathrm{x}$ is determined by the TFN membership function:

$$
\begin{aligned}
\mathrm{f}_{\mathrm{A}}(\mathrm{x}) & =1, & & \mathrm{x}=\mathrm{m} \\
& =\frac{\mathrm{x}-1}{\mathrm{~m}-1}, & & 1 \leq \mathrm{x} \leq \mathrm{m} \\
& =\frac{\mathrm{r}-\mathrm{x},}{\mathrm{r}-\mathrm{m}} & & \mathrm{m} \leq \mathrm{x} \leq \mathrm{r} \\
& =0, & & \mathrm{x}>\mathrm{r}
\end{aligned}
$$

Fuzzy Linguistic label consists of the categories of Very Low, Low, Medium, High, and Very High. According to Pedrycz and Gomide (1998), fuzzy linguistic label interval obtained from interviews with experts. The results of expert interviews obtained very low with the interval from 0 to 0.25 , low with the interval from 0 to 0.5 , medium with the interval from 0.25 to 0.75 , high with the interval from 0.5 to 1.0 , and very high with the interval from 0.75 to 1.0 .

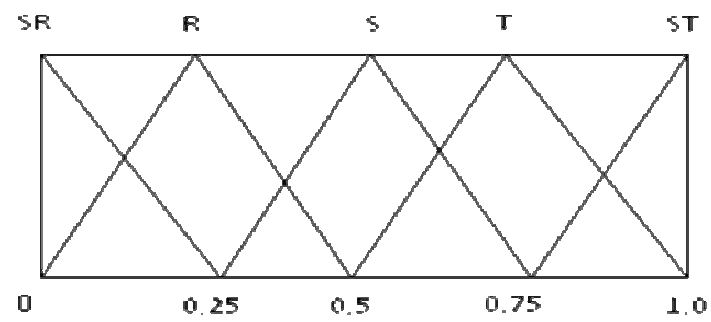

Figure 5 Fuzzy Membership Function for Fuzzy Rating of Paddy Farmer Postharvest Activities and Fuzzy Linguistic Label

Results of fuzzy linguistic label and fuzzy rating of paddy farmer postharvest activities are then aggregated using the Multi-Expert Multi-Criteria Decision Making by Ordered weighed Average (OWA). Aggregation is conducted in two stages, i.e. the criteria aggregation and expert aggregation. This aggregation is then ended with expert aggregation. Expert aggregation results in the level of paddy farmer post-harvest technological capability in dealing with climate change.

Aggregation is done in two stages, sub-criteria/criteria aggregation and aggregation experts. Yager (1993) formulate criteria aggregation as follows: 
$\mathrm{P}_{\mathrm{ik}}=\operatorname{Min}_{\mathrm{j}}\left[\operatorname{Neg}\left(\mathrm{I}\left(\mathrm{q}_{\mathrm{j}}\right)\right) \vee \mathrm{P}_{\mathrm{ik}}\left(\mathrm{q}_{\mathrm{j}}\right)\right]$

As the formula for the experts aggregation is as follows:

$\mathrm{P}=$ Maks $_{\mathrm{j}=1, \ldots, 6}\left[\mathrm{Q}_{(\mathrm{j})} \wedge \mathrm{B}_{\mathrm{J}}\right] \ldots$

\section{RESULTS AND DISCUSSION}

Hierarchical structure of farmer postharvest technological capability measurement in dealing with climate change is derived from the technological capability developed by Ernst et al (1998), as well as from brainstorming and in-depth interviews with several experts in paddy postharvest and climate change. Hierarchical structure consists of 3 (three) levels which include purpose in the first level, criterion in the second level, and sub-criteria in the third level.

a. First Level: Purpose

The hierarchy at the first level describes the purpose of the activity. The purpose is to measure the paddy farmer post-harvest technological capability in dealing with climate change.

b. Level Two: Criteria

The criteria used to measure the technological capability of paddy farmer post-harvest activities in dealing with climate change consists of production capability $\left(\mathrm{KTP}_{1}\right)$, investment capability $\left(\mathrm{KTP}_{2}\right)$, capability to make small changes $\left(\mathrm{KTP}_{3}\right)$, capability to make major changes $\left(\mathrm{KTP}_{4}\right)$, marketing capability $\left(\mathrm{KTP}_{5}\right)$, and the capability to create network $\left(\mathrm{KTP}_{6}\right)$.

c. Level Three: Sub Criteria

Sub criteria used to measure the farmer post-harvest technological capability in dealing with climate change can be seen in Table 1.

Table 1 Sub Criteria of Paddy Farmer Post Harvest Technological Capabilities in Dealing wth Climate Change

\begin{tabular}{|c|c|c|c|}
\hline No & Criteria & \multicolumn{2}{|c|}{ Sub Criteria } \\
\hline \multirow{5}{*}{1} & \multirow{5}{*}{$\begin{array}{l}\text { Production } \\
\text { Capabilities }\left(\mathrm{KTP}_{1}\right)\end{array}$} & $\left(\mathrm{SKTP}_{1}\right)$ & The ability of farmers in post-harvest activities \\
\hline & & $\left(\mathrm{SKTP}_{2}\right)$ & The ability of farmers on controlling the quality of grain \\
\hline & & $\left(\mathrm{SKTP}_{3}\right)$ & $\begin{array}{l}\text { The ability of farmers in scheduling paddy post-harvest } \\
\text { activities }\end{array}$ \\
\hline & & $\left(\mathrm{SKTP}_{4}\right)$ & $\begin{array}{l}\text { The ability of farmers in solving the problems related to paddy } \\
\text { post-harvest activities }\end{array}$ \\
\hline & & $\left(\mathrm{SKTP}_{5}\right)$ & $\begin{array}{l}\text { The ability of farmers in repairing and maintaining machinery } \\
\text { and equipment }\end{array}$ \\
\hline 2 & $\begin{array}{l}\text { Investment } \\
\text { Capabilities }\left(\mathrm{KTP}_{2}\right)\end{array}$ & - & - \\
\hline & The capability to & $\left(\mathrm{SKTP}_{6}\right)$ & $\begin{array}{l}\text { Farmers' ability to modify the machines to increase the rice } \\
\text { post-harvest capability }\end{array}$ \\
\hline & changes $\left(\mathrm{KTP}_{3}\right)$ & $\left(\mathrm{SKTP}_{7}\right)$ & $\begin{array}{l}\text { The ability of farmers to create working procedures in } \\
\text { harvesting paddy }\end{array}$ \\
\hline & The capability to & $\left(\mathrm{SKTP}_{8}\right)$ & $\begin{array}{l}\text { The ability of farmers to produce the machine/ technology for } \\
\text { paddy postharvest activities to reduce weight loss and quality } \\
\text { due to climate change }\end{array}$ \\
\hline & changes $\left(\mathrm{KTP}_{4}\right)$ & $\left(\mathrm{SKTP}_{9}\right)$ & $\begin{array}{l}\text { The ability of farmers to create new process in paddy post- } \\
\text { harvest activities to anticipate weight loss and reduced grain } \\
\text { quality in facing climate change. }\end{array}$ \\
\hline 5 & $\begin{array}{l}\text { Marketing } \\
\text { Capabilities }\left(\mathrm{KTP}_{5}\right)\end{array}$ & - & - \\
\hline 6 & $\begin{array}{l}\text { The Capability to } \\
\text { create network } \\
\left(\mathrm{KTP}_{6}\right)\end{array}$ & - & - \\
\hline
\end{tabular}


Weights of criteria and sub-criteria are generated using expert choice 2000 software. The weights are then converted into fuzzy form using TFN membership functions as shown in Figure 5.

Table 2 Weight and Fuzzy Linguistic Label

\begin{tabular}{|c|c|c|c|c|c|}
\hline Criteria & Weight & $\begin{array}{c}\text { Fuzzy Linguistic } \\
\text { Label }\end{array}$ & Sub Criteria & Weight & $\begin{array}{c}\text { Fuzzy Linguistic } \\
\text { Fuzzy }\end{array}$ \\
\hline \multirow{5}{*}{$\mathrm{KTP}_{1}$} & \multirow{5}{*}{0,266} & \multirow{5}{*}{$\mathrm{R}$} & $\mathrm{SKTP}_{1}$ & 0,402 & S \\
\hline & & & $\mathrm{SKTP}_{2}$ & 0,215 & $\mathrm{R}$ \\
\hline & & & $\mathrm{SKTP}_{3}$ & 0,180 & $\mathrm{R}$ \\
\hline & & & $\mathrm{SKTP}_{4}$ & 0,125 & $\mathrm{R}$ \\
\hline & & & $\mathrm{SKTP}_{5}$ & 0,077 & SR \\
\hline $\mathrm{KTP}_{2}$ & 0,074 & SR & - & - & - \\
\hline \multirow{2}{*}{$\mathrm{KTP}_{3}$} & \multirow{2}{*}{0,097} & \multirow{2}{*}{ SR } & $\mathrm{SKTP}_{6}$ & 0,746 & $\mathrm{~T}$ \\
\hline & & & $\mathrm{SKTP}_{7}$ & 0,254 & $\mathrm{R}$ \\
\hline \multirow{2}{*}{$\mathrm{KTP}_{4}$} & \multirow{2}{*}{0,071} & \multirow{2}{*}{ SR } & $\mathrm{SKTP}_{8}$ & 0,532 & S \\
\hline & & & $\mathrm{SKTP}_{9}$ & 0,468 & S \\
\hline $\mathrm{KTP}_{5}$ & 0,253 & $\mathrm{R}$ & - & - & - \\
\hline $\mathrm{KTP}_{6}$ & 0,238 & $\mathrm{R}$ & - & - & - \\
\hline
\end{tabular}

$\mathrm{KTP}_{3}$ criteria consist of $\mathrm{SKTP}_{6}$ and $\mathrm{SKTP}_{7}$ sub criteria. $\mathrm{SKTP}_{6}$ has a weight of 0.746 , while $\mathrm{SKTP}_{7}$ weighs 0.254 . Weight of 0.746 on $\mathrm{SKTP}_{6}$ lies in the medium and high category of fuzzy membership values. Using TFN membership functions as shown in Figure 5, the medium and high category of the fuzzy membership value in $\mathrm{SKTP}_{6}$ can be calculated.

$$
\begin{aligned}
& \text { Medium }=\frac{-75-0,746}{\frac{1.75-0.5}{1}=0,016} \\
& \text { High }=\frac{0,746-0,5}{0,75-0,5}=0,984
\end{aligned}
$$

The fuzzy membership value in the medium category is 0.016 , while the category of high is 0.984 . Fuzzy membership value in high category is bigger than the value in medium category. It suggests that fuzzy linguistic label for $\mathrm{SKTP}_{6}$ is high.

The next step after determination of fuzzy linguistic label is fuzzy rating of paddy farmer postharvest activities conducted by experts. The last step is aggregation of fuzzy linguistic label and fuzzy rating which is conducted in farmer post-harvest activities. Aggregation fuzzy linguistic label and fuzzy rating which is conducted in farmer post-harvest activities such as paddy harvesting, grain threshing, grain drying, and grain storage. As for the other activities, since they only have one criterion and have no sub criteria, the aggregation using fuzzy rating is applied only on experts. Result of the aggregation is the level of paddy farmer post-harvest technological capability in dealing with climate change. 
Table 3 Levels of Paddy Farmer Postharvest Technological Capabilities in Dealing with Climate Change

\begin{tabular}{|c|c|c|}
\hline No & Post Harvest Activities & Technological Capability Level \\
\hline 1 & Paddy Harvesting & High \\
\hline 2 & Grain Threshing & High \\
\hline 3 & Grain Drying & High \\
\hline 4 & Grain Storage & High \\
\hline 5 & Marketing Cooperation with Paddy Milling Industry & High \\
\hline 6 & Marketing cooperation with Trader & High \\
\hline 7 & Developing Relationship with Other Farmers & Medium \\
\hline 8 & Developing Relationship with Paddy Milling Industry & High \\
\hline 9 & Developing Relationship with R \& D and University & Medium \\
\hline 10 & Developing Relationship with BMKG & Medium \\
\hline 11 & $\begin{array}{l}\text { Developing Relationship with the Agricultural } \\
\text { Equipment Provider Industry }\end{array}$ & Medium \\
\hline 12 & Developing Relationship with Traders & High \\
\hline 13 & Developing Relationship with Agricultural Instructor & High \\
\hline
\end{tabular}

The level of paddy farmer post-harvest technological capability in dealing with climate change resulted from the aggregation is then validated by experts. The result of validation by experts showed that there is discrepancy between the obtained results and the expert knowledge. According to experts, the level of farmer post-harvest technological capabilities in dealing with climate change for the activities of rice harvesting, grain threshing, grain drying and storage grain is medium.

Invalidity in the activities of paddy harvesting, grain threshing, grain drying, and grain storage is then verified more deeply to get the level of technological capability. At the stage of determination of criteria weight, it is found that paddy harvesting, grain threshing, grain drying, and grain storage are only influenced by the criteria of $\mathrm{KTP}_{1}, \mathrm{KTP}_{2}, \mathrm{KTP}_{3}$, and $\mathrm{KTP}_{4}$. Criteria of $\mathrm{KTP}_{5}$ and $\mathrm{KTP}_{6}$ do not influence the four activities.

Taking into consideration that some criteria influence and some other do not influence the activities, the criteria that have no influence on the activities is eliminated. Since $\mathrm{KTP}_{5}$ and $\mathrm{KTP}_{6}$ criteria are eliminated, total value of $\mathrm{KTP}_{1}, \mathrm{KTP}_{2}, \mathrm{KTP}_{3}$, and $\mathrm{KTP}_{4}$ criteria is less than one. To reach the total value equals to one, the criteria of $\mathrm{KTP}_{1}, \mathrm{KTP}_{2}, \mathrm{KTP}_{3}$, and $\mathrm{KTP}_{4}$ is normalized. The result of this weight normalization is later used in data processing. 
Table 4 Weights and Fuzzy Linguistic Label Resulted from Normalization

\begin{tabular}{|c|c|c|c|c|c|}
\hline Criteria & Weight & Fuzzy Linguistic Label & Sub Criteria & Weight & Fuzzy Linguistic Label \\
\hline \multirow{5}{*}{$\mathrm{KTP}_{1}$} & \multirow{5}{*}{0,524} & \multirow{5}{*}{$\mathrm{S}$} & $\mathrm{SKTP}_{1}$ & 0,402 & S \\
\hline & & & $\mathrm{SKTP}_{2}$ & 0,215 & $\mathrm{R}$ \\
\hline & & & $\mathrm{SKTP}_{3}$ & 0,180 & $\mathrm{R}$ \\
\hline & & & $\mathrm{SKTP}_{4}$ & 0,125 & $\mathrm{R}$ \\
\hline & & & $\mathrm{SKTP}_{5}$ & 0,077 & SR \\
\hline $\mathrm{KTP}_{2}$ & 0,146 & $\mathrm{R}$ & - & - & - \\
\hline \multirow{2}{*}{$\mathrm{KTP}_{3}$} & \multirow{2}{*}{0,191} & \multirow{2}{*}{$\mathrm{R}$} & $\mathrm{SKTP}_{6}$ & 0,746 & $\mathrm{~T}$ \\
\hline & & & $\mathrm{SKTP}_{7}$ & 0,254 & $\mathrm{R}$ \\
\hline \multirow{2}{*}{$\mathrm{KTP}_{4}$} & \multirow{2}{*}{0,139} & \multirow{2}{*}{$\mathrm{R}$} & $\mathrm{SKTP}_{8}$ & 0,532 & $\mathrm{~S}$ \\
\hline & & & $\mathrm{SKTP}_{9}$ & 0,468 & $S$ \\
\hline
\end{tabular}

Weights and fuzzy linguistic label resulted from normalization process are then aggregated using fuzzy rating on paddy farmer postharvest activities. This aggregation results in the level of paddy farmer post-harvest technological capability in dealing with climate change as shown in Table 5.

Table 5 Level of Farmer Post-Harvest Technological Capabilities in Dealing with Climate Change Resulted from Normalization of $\mathrm{KTP}_{1}, \mathrm{KTP}_{2}, \mathrm{KTP}_{3}$, and $\mathrm{KTP}_{4}$ Criteria

\begin{tabular}{|c|c|c|}
\hline No & Post Harvest Activities & Technological Capability Level \\
\hline 1 & Paddy Harvesting & Medium \\
\hline 2 & Grain Threshing & Medium \\
\hline 3 & Grain Drying & Medium \\
\hline 4 & Grain Storage & High \\
\hline 5 & Marketing Cooperation with Paddy Milling Industry & High \\
\hline 6 & Marketing cooperation with Trader & High \\
\hline 7 & Developing Relationship with Other Farmers & Medium \\
\hline 8 & Developing Relationship with Paddy Milling Industry & Medium \\
\hline 9 & Developing Relationship with R \& D and University & Medium \\
\hline 10 & Developing Relationship with BMKG & High \\
\hline 11 & Developing Relationship with the Agricultural & High \\
\hline 12 & Equipment Provider Industry & \\
\hline 13 & Developing Relationship with Agricultural Instructor & \\
\hline
\end{tabular}

The level of farmer post-harvest technological capabilities in dealing with climate change resulted from normalization of $\mathrm{KTP}_{1}, \mathrm{KTP}_{2}, \mathrm{KTP}_{3}$ and $\mathrm{KTP}_{4}$ criteria is evidently already in accordance with the level of 
technological capabilities resulted from expert validation. It suggests that if the criteria having no influence on post-harvest activities are included in the data processing, it will influence the final result of data processing. The non-influencing criteria are first eliminated, and followed by the normalization of the influencing criteria to reach the total value of weight equals to one. The result of weight normalization is continued to the next stages, i.e. determination of fuzzy linguistic label, fuzzy rating on farmer post-harvest activities, and the determination of technological capability level using aggregation of fuzzy linguistic label and fuzzy rating on farmer postharvest activities.

\section{CONCLUSION}

\section{Conclusion}

One of the efforts can be conducted to deal with climate change on paddy post-harvest activities is by improving the post-harvest technological capability. Technological capability can be increased if the level of technological capabilities is known. Measurement of technological capability is required to find out the level of technological capability. Model for measuring post-harvest technological technology of paddy farmers in dealing with climate change is a model designed to measure farmer post-harvest technological technology in dealing with climate change. The output generated from this model is the level of technological capabilities in dealing with climate change on each post-harvest activity. The level of technological capability resulted from this model can be generally divided into two levels, high and medium. There is a high level of technological capability in the activities of marketing cooperation with milling industry and rice traders, and developing relationship with milling industry, traders, and agricultural instructor. As for the medium level of technological capability, it is found in the activities of paddy harvesting, grain threshing, grain drying, grain storage, marketing cooperation with other farmers, and developing relationships with R \& D institutions and university, BMKG, and agricultural equipment provider industry.

\section{Recommendition}

Improvement of paddy farmer post-harvest technological capability in dealing with climate change should focus on technologies in the medium level. After the technological capability in medium level is able to be increased to high level, it is advisable to undertake remeasurement on technology capabilities more carefully to identify what other technologies need to be improved to help farmers dealing with climate change.

\section{BIBLIOGRAPHY}

Bell, M. and Pavitt, K. 1993. Technological Accumulation and Industrial Growth: Contrasts between Developed and Developing Countries. Industrial and Corporate Change 2 (1): 157-210.

Dutrenit, G. , 2004. Building Technological Capabilities in Latecomer Firms: A Review Essay. Science, Technology and Society 9 (2): 209-241.

Eriyatno, Sofyar F. 2007. Policy Research of Research Method for Post Graduated Student. Bogor: IPB Press.

Ernst D, Ganiatsos T, L. Mytelka , 1998. Technological Capabilities in the Context of Export-led Growth: A Conceptual Framework, in Ernst, Ganiatsos, and Mytelka, Technological Capabilities and Export Success in Asia. London: Rotledge.

Iammarino, S., Padilla-Perez, R. and von Tunzelmann, N. , 2008. Technological Capabilities and Global-Local Interactions: The Electronics Industry in Two Mexican Regions. World Development 36 (10): 1980-2003.

Iswari K. 2012. Readiness of Harvest and Post-Harvest Technology of Paddy to Minimize Yield Loss and Improve the Quality of Rice. Agriculture Research and Development Journal 31 (2): 58 - 67.

Kim L. 1997. From imitation to innovation: The dynamics of Korea's Technological Learning. Boston, MA: Harvard Business School Press.

Kim L. 1999. Building Technological Capabilities for Industrialization: Analytical Frameworks and Korea's Experience. Industrial and Corporate Change 8 (1): 111-136.

Lall S. 1992. Technological Capabilities and Industrialisation. World Development 20: 165-186.

Lall S. 1993. Promoting Technology Development: The Role of Technology Transfer and Indigenous Effort. Third World Quarterly 14 (1): 95-108.

Las I. et al. 2011. Anticipation of Climate Change in Securing National Rice Production. Agricultural Innovation Development 4 (1).

Pedrycz W, Gomide F. 1998. An Introduction to Fuzzy Sets Analysis and Design. London: Massachusetts Institute of Technology Press.

Rohkani. 2007. Reduction of Postharvest Losses National Movement, an Attempt to Cope with Food Crisis. Agrimedia Magazine 12 (2): 21-30. 
Setyono A. 2010. Postharvest Technology Improvement to Minimize Paddy Yield Los. Agriculture Innovation Development Journal 3 (3): 212 - 226.

Szogs A. 2010. Technology Transfer and Technological Capability Building in Informal Firms in Tanzania. [Dissertation]. Sweden: Lund University.

Tahir R. , 2010. Revitalization Through Innovation PenyosohanMendukung Rice Milling Rice Self-Sufficiency and Global Competition. Agricultural Innovation Development 3 (3): 171-183.

Wang J.J, Jing Y.Y, Zhang C.F, Shi G.H, Zhang X.T. 2008. A Fuzzy Multi Criteria Decision Making Model for Trigeneration System. Energy Policy 36: 3823 - 2832.

Yager R.R. 1993. Non-Numeric Multi-Criteria Multi-Person Decision Making. Group Decision and Negotiation 2: $81-93$. 